\title{
A Tributação das Operações com Gás Liquefeito Derivado do Gás Natural
}

Fabricio do Rozario Valle Dantas Leite'

\section{Introdução}

A tributação das operações com Gás Liquefeito derivado do Gás Natural apresenta peculiaridades que ensejaram tratamento específico na Constituição da República de 1988. Todavia, surgiram conflitos entre os Estados produtores e consumidores acerca do produto da arrecadação do ICMS incidente nestas operações, o que culminou com a celebração do Protocolo no 33/2003.

O referido Protocolo foi celebrado, no âmbito do Conselho Nacional de Política Fazendária (CONFAZ), pelos Estados de Alagoas, Amazonas, Bahia, Ceará, Maranhão, Pará, Pernambuco, Rio de Janeiro, Rio Grande do Norte e Sergipe, tratando sobre os "procedimentos nas operações interestaduais com Gás Liquefeito de Petróleo - GLP, derivado de Gás Natural tributado na forma estabelecida pelo Convênio ICMS 03/99".

Ainda assim, o Estado do Piauí, dentre outros, questionou a constitucionalidade do Protocolo, ajuizando a Ação Direta de Inconstitucionalidade no 3.103-1. Recentemente, o Supremo Tribunal Federal, ao julgar a citada ADI, entendeu ser constitucionais as disposições do Protocolo $n^{\circ} 33 / 2003$ que prescreveram deveres instrumentais, ou obrigações acessórias, nas operaçōes com Gás Liquefeito de Petróleo derivado de gás natural, sujeitas à substituição tributária prevista no Convênio ICMS nº 3/99.

Face à relevância do tema, busca-se com o presente artigo tecer algumas considerações sobre os principais aspectos da tributação das operações com Gás

\footnotetext{
Procurador do Estado do Rio de Janeiro. Subsecretário de Fazenda para Assuntos Jurídicos. Professor contratado de Direito Processual Tributário da UERJ. Advogado.
} 
Liquefeito derivado do Gás Natural, bem como analisar a atual jurisprudência sobre o assunto.

\section{Da sistemática de produção do gás liquefeito derivado de gás natural (GLGN)}

A exploração e produção de petróleo e gás natural é uma atividade industrial que compreende diversas fases, da pesquisa geológica à extração e transporte para refino. A todo este processo dá-se o nome de upstream (em oposição à fase de distribuição e revenda de derivados, conhecida como downstream). Durante boa parte desta atividade, as exploraçōes econômicas do petróleo e do gás natural caminham lado a lado. Isso não quer dizer, contudo, que se possam equiparar os dois produtos.

O gás natural é um combustível fóssil composto de uma mistura de gases inorgânicos e hidrocarbonetos, predominando o metano e, em menores quantidades (dentre outros), propano e butano. É mais leve do que o ar e tem alta capacidade de dispersão na atmosfera, sendo encontrado em rochas porosas no subsolo, associado ou não ao petróleo. No primeiro caso, o gás está, no reservatório, dissolvido no óleo ou formando uma capa de gás. O gás não associado, por sua vez, está livre de petróleo no reservatório (ou o óleo existente é em pequena quantidade). ${ }^{2}$

Confirmada a existência de petróleo e gás natural num campo, têm início as fases de desenvolvimento e de produçāo. Até este ponto, as indústrias de petróleo e gás natural caminham juntas. Mas as diferenças começam já nas unidades de produção, quando uma parcela do gás é utilizada como gás lift com o objetivo de reduzir a densidade do petróleo, facilitando sua extração. Outra parcela é reinjetada nos poços com duas finalidades básicas: armazenamento em poços de gás não associados ao petróleo, e reinjetamento nos reservatórios para aumentar a sua pressão interna (recuperação secundária).

Excluída a parcela de gás queimada em flares (destruída por não haver infraestrutura adequada ao seu aproveitamento), o restante do gás pode ser consumido internamente na geração de eletricidade e vapor para aquele projeto de explo-

\footnotetext{
2 A Agência Nacional do Petróleo, Gás Natural e Biocombustíveis (ANP) assim define o gás natural: "Gás Natural ou Gás - todo hidrocarboneto ou mistura de hidrocarbonetos que permaneça em estado gasoso ou dissolvido no óleo nas condições originais do reservatório, e que se mantenha no estado gasoso nas condiçōes atmosféricas normais. É extraído diretamente de reservatórios petrolíferos ou gaseiferos, incluindo gases úmidos, secos, residuais e gases raros (gases nobres). Ao processar o gás natural úmido nas UPGNs, sāo obtidos os seguintes produtos: (i) o gás seco (também conhecido como gás residual); e (ii) o líquido de gás natural (LGN), que contém propano (C3) e butano (C4) (que formam o gás liquefeito de petróleo - GLP) e a gasolina natural $(\mathrm{C} 5+)$ " (<http://www.anp.gov. br/glossario/index.asp? strAlpha $=G>$. Acesso em: 22 set. 2006).
} 
ração. Contudo, a verdadeira exploração comercial do gás natural começa quando ele é escoado para Unidades de Processamento de Gás Natural (UPGNs). ${ }^{3}$

Este gás levado às UPGNs é a parcela que, de fato, terá aproveitamento econômico autônomo. Nestas unidades ocorre a desidratação do gás natural e separação das suas frações mais leves, num processo em que são obtidos o gás natural seco (metano e etano), a gasolina natural (pentano e superiores) e o Gás Liquefeito de Petróleo - GLP (propano e butano).

Todavia, a nomenclatura GLP para o gás liquefeito derivado do gás natural pode gerar equívocos, inclusive para o entendimento da própria operação. Isto porque, embora denominado GLP (Gás Liquefeito de Petróleo), também é possível obtê-lo a partir de gás natural, de modo que se utiliza o nome GLP para designar produto que não é obtido do petróleo.

A rigor, embora tenha as mesmas características do gás derivado do petróleo (GLP), o gás liquefeito derivado do gás natural deveria ter esta outra denominação, mais compatível com sua origem. Sugere-se, portanto, a nova nomenclatura de Gás Liquefeito Derivado de Gás Natural (GLGN), conforme o seguinte esquema:

$$
\text { Gás Liquefeito (GL) }\left\{\begin{array}{l}
\text { Petróleo - GLP } \\
\text { Gás Natural - GLGN }
\end{array}\right.
$$

A compreensão do que se acaba de expor é condição essencial a um correto enquadramento das operaçōes relacionadas com a exploração do GL para fins de aplicação da legislação tributária. Conforme a origem do GL - petróleo ou gás natural -, variará a incidência do ICMS, como se passa a demonstrar.

\section{Do tratamento tributário dispensado ao gás liquefeito derivado do gás natural}

O gás liquefeito derivado do gás natural tem tratamento específico na Constituição da República, apartado do dispensado aos produtos derivados do petróleo, como o GLP.

Antes da promulgação da Constituição de 1988, onerava as operaçōes de venda de combustíveis - sem se cogitar de sua espécie - apenas o IUCLG (Imposto Único Sobre Combustíveis Líquidos e Gasosos), de competência da União e in-

3 LEMOS, Luiz Antônio de Maia. A estrutura contratual da indústria de transporte de gás. In: RIBEIRO, Marilda (Coord.). Estudos e pareceres: direito do petróleo e gás. Rio de Janeiro: Renovar, 2005, p. $211-212$. 
cidente uma única vez no preço das refinarias. ${ }^{4} \mathrm{~A}$ CR/88 compartilhou entre a Uniāo e os Estados a competência impositiva sobre operações com petróleo, gás natural e seus combustíveis derivados.

Desde a redação original da atual Carta da República, diferentemente do que ocorria até então, já se previa instrumental que atribui aos derivados do petróleo e aos derivados do gás natural disciplina diversa. Em nenhum momento houve a equiparação entre eles.

Assim, determina o artigo $155, \$ 2^{\circ}, \mathrm{X}, b$, da Constituição Federal que o ICMS não incide "sobre operações que destinem a outros Estados petróleo, inclusive lubrificantes, combustiveis líquidos e gasosos dele derivados, e energia elétrica" (grifos nossos). É notória, portanto, a clara intenção do constituinte de 1988 estabelecer nova regulação para a matéria, instituindo previsão específica para combustíveis derivados do petróleo. ${ }^{5}$

A conclusão que daí se extrai é inequívoca: o constituinte estabeleceu tratamento especial para o petróleo e combustíveis e lubrificantes dele derivados. Vale frisar: derivados de petróleo, não de gás natural. Todavia, nada dispôs sobre os produtos derivados de gás natural, assim como não o fez em relação a centenas de produtos - verbi gratia, o álcool. Rompeu, desta forma, com a sistemática constitucional anterior, segundo a qual todos os combustíveis usufruíam o mesmo tratamento.

Isso não autoriza a conclusão, por óbvio, de que estariam o gás natural, o gás liquefeito derivado de gás natural ou outro produto oriundo do aproveitamento econômico do gás natural compreendidos na disposição regulatória do petróleo.

A Lei $n^{\circ}$ 9.478/97 estabeleceu novo marco regulatório sobre o setor do petróleo e gás natural no Brasil, estabelecendo definições básicas dos termos empregados nas diversas atividades compreendidas no ciclo de exploração e produção de petróleo e gás natural. ${ }^{6}$ É a própria Lei $n^{\circ}$ 9.478/97 (art. $6^{\circ}$ ) que define petróleo

\footnotetext{
+ SILVEIRA FILHO, Guido Rogério Macedo e OLIVEIRA, Jorge Luiz. Distorçōes/contestações tributárias no mercado de combustiveis. In: RIBEIRO, Marilda (Coord.), Estudos e pareceres: direito do petróleo e gás. Rio de Janeiro: Renovar, 2005, p. 234.

"Retirando-se as operaçōes relativas a combustiveis, lubrificantes e energia elétrica do âmbito de abrangência do antigo ICM e de eventuais outros impostos (inclusive da competência residual da Uniāo), tinha-se em mira evitar que Estados e Municípios, por meio de uma tributaçāo discricionária, viessem a criar dificuldades à expansāo das indústrias no País" (CARRAZZA, Roque Antonio. ICMS. 11. ed. São Paulo: Malheiros, 2006, p. 223).

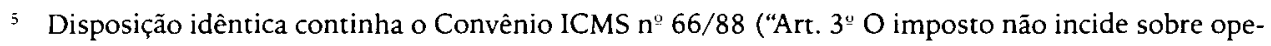
raçāo: [...] II - que destine a outro Estado petróleo, inclusive lubrificantes, combustíveis líquidos e gasosos dele derivados, e energia elétrica;"), bem como a atual Lei Complementar $n^{\circ}$ 87/96 ("Art. 3." O imposto não incide sobre: [...] III - operaçōes interestaduais relativas a energia elétrica e petróleo, inclusive lubrificantes e combustíveis líquidos e gasosos dele derivados, quando destinados à industrialização ou à comercialização").

6 Art. $6^{\circ}$ Para os fins desta Lei e de sua regulamentaçāo, ficam estabelecidas as seguintes definiçōes:

I - Petróleo: todo e qualquer hidrocarboneto líquido em seu estado natural, a exemplo do óleo cru e condensado;
} 
e gás natural, distinguindo-os e excluindo expressamente dos derivados de petróleo os produtos decorrentes da exploração do gás natural.

Os juristas que se dedicam ao estudo dos aspectos jurídicos presentes na indústria do petróleo e do gás também enfatizam as diferenças entre os dois produtos. Neste contexto, discorre a Prof ${ }^{a}$ Marilda Rosado sobre a definição de petróleo: "O petróleo é uma substância fluida, que tem como uma de suas principais características a mobilidade, tanto maior quanto menos viscoso for. As qualidades do óleo são classificadas de acordo com a densidade e a viscosidade. Assim, quanto mais pesado o óleo, mais dificil é a sua extração e menor o seu valor comercial. Os programas de recuperação levam em conta todos esses fatores. A recuperação do óleo cru é muito complexa, pois ele se encontra acumulado nos espaços porosos das rochas-reservatório sob grande pressão, e quando se perfura um poço, cria-se uma área de baixa pressão. É a diferença de pressão que impulsiona o fluxo do óleo para o poço" (grifo nosso). ${ }^{7}$

Pela descrição dada, é indiscutível a diferença a ser dada ao petróleo e ao gás natural. É até mesmo inviável pensar-se em "viscosidade" quando se faz referência ao gás, de sorte que a indústria, de há muito, reconhece este fato e lida de forma distinta com petróleo e com gás natural (e derivados de um e de outro).

II - Gás Natural ou Gás: todo hidrocarboneto que permaneça em estado gasoso nas condições atmosféricas normais, extraido diretamente a partir de reservatórios petrolíferos ou gaseíferos, incluindo gases úmidos, secos, residuais e gases raros;

III - Derivados de Petróleo: produtos decorrentes da transformação do petróleo;

IV - Derivados Básicos: principais derivados de petróleo, referidos no art. 177 da Constituiçāo Federal, a serem classificados pela Agência Nacional do Petróleo;

V - Refino ou Refinação: conjunto de processos destinados a transformar o petróleo em derivados de petróleo;

VI - Tratamento ou Processamento de Gás Natural: conjunto de operaçōes destinadas a permitir o seu transporte, distribuição e utilização;

VII - Transporte: movimentaçāo de petróleo e seus derivados ou gás natural em meio ou percurso considerado de interesse geral;

$[\ldots]$

$\mathrm{X}$ - Reservatório ou Depósito: configuração geológica dotada de propriedades específicas, armazenadora de petróleo ou gás, associados ou não;

$[\ldots]$

XIX - Indústria do Petróleo: conjunto de atividades econômicas relacionadas com a exploração, desenvolvimento, produção, refino, processamento, transporte, importação e exportaçāo de petróleo, gás natural e outros hidrocarbonetos fluidos e seus derivados;

$[\ldots]$

XXII - Distribuiçāo de Gás Canalizado: serviços locais de comercialização de gás canalizado, junto aos usuários finais, explorados com exclusividade pelos Estados, diretamente ou mediante concessão, nos termos do $\$ 2^{\circ}$ do art. 25 da Constituiçāo Federal;

XXIII - Estocagem de Gás Natural: armazenamento de gás natural em reservatórios próprios, formaçōes naturais ou artificiais."

RIBEIRO, Marilda Rosado de Sá, Introduçāo à unitizaçāo de reservatórios petrolíferos. In: RIBEIRO, Marilda (Coord.). Estudos e pareceres: direito do petróleo e gás. Rio de Janeiro: Renovar, 2005, p. 127-128. 
O ordenamento jurídico, portanto, instituiu tratamento diferenciado sobre as fontes energéticas derivadas de hidrocarbonetos, conforme a sua origem. Devemse sempre ter em mira as regras mais básicas de hermenêutica, dentre as quais as de que a lei não contém palavras inúteis e, se ela fez uma distinção, o intérprete não a pode ignorar. A distinção, inclusive, é expressa.

Do ponto de vista legal, chamam-se derivados de petróleo apenas aqueles produtos decorrentes da transformaçāo do petróleo - hidrocarboneto líquido. ${ }^{8}$ Por outro lado, produtos que, a exemplo do GL, possam ser obtidos a partir de petróleo ou de gás natural apenas poderão ser considerados derivados de petróleo caso sejam obtidos a partir de petróleo, não de gás natural. Isto se reflete na tributação sobre operações que envolvam estes produtos.

A lei contempla, portanto, distinçōes nítidas que refletem as próprias características físicas dos produtos envolvidos.

Sempre que a lei - aí abrangida a Constituição - conferir determinado tratamento a petróleo e seus derivados, isso não compreenderá os produtos derivados do gás natural. Com efeito, a Lei no 9.748/97 não criou a distinção, mas apenas explicitou tratamento que vem desde a Carta de 1988.

E assim é em diversos pontos do ordenamento. Produtos derivados do petróleo - dentre o que se inclui o gás liquefeito - não devem ser confundidos com os derivados do gás natural, ainda que sejam usualmente denominados da mesma forma. Acumulam-se os exemplos em que o Direito reconhece a distinção. ${ }^{9}$ Aliás, quando o legislador pretende dar o mesmo tratamento ao gás liquefeito derivado de petróleo e ao derivado de gás natural, ele o faz sempre de forma expressa, porque indiscutível a diferença, do ponto de vista jurídico. ${ }^{10}$

\footnotetext{
8 "Petróleo - todo e qualquer hidrocarboneto líquido em seu estado natural, a exemplo do óleo cru e condensado" (<http://www.anp.gov.br/glossario/index.asp? strAlpha=P>. Acesso em: 22 set. 2006).

9 Veja-se, à guisa de ilustração, a Lei $n^{\circ}$ 9.718, de 27 de novembro de 1998: “Art. $4^{\circ}$ As contribuiçōes para os Programas de Integraçāo Social e de Formação do Patrimônio do Servidor Público - PIS/PASEP e para o Financiamento da Seguridade Social - COFINS devidas pelos produtores e importadores de derivados de petróleo serão calculadas, respectivamente, com base nas seguintes alíquotas: (Redaçãa dada pela Lei $n^{\circ} 10.865$, de 2004) [...]

III - 10,2\% (dez inteiros e dois décimos por cento) e 47,4\% (quarenta e sete inteiros e quatro décimos por cento) incidentes sobre a receita bruta decorrente da venda de gás liquefeito de petróleo - GLP derivado de petróleo e de gás natural;"

10 Da mesma forma, a Lei $n^{\circ}$ 10.336/2001 (que institui a Contribuiçāo de Intervenção no Domínio Econômico incidente sobre a importação e a comercialização de petróleo e seus derivados, gás natural e seus derivados, e álcool etílico combustível (CIDE), a que se refere os arts. 149 e 177 da Constituiçāo Federal, com a redaçāo dada pela Emenda Constitucional $n^{2} 33$, de 11 de dezembro de 2001) faz referência tanto aos derivados do petróleo como aos derivados do gás natural (art. $1^{2}$ ). A lei reconhece, ainda, e de forma expressa, a distinção entre o gás liquefeito derivado do petróleo e o derivado do gás natural, como se verifica no estabelecimento dos fatos geradores:

"Art. 3ㅇ A Cide tem como fatos geradores as operaçōes, realizadas pelos contribuintes referidos no art. 2 , de importação e de comercialização no mercado interno de:

[...]

V - gás liquefeito de petróleo, inclusive o derivado de gás natural e de nafta; [...]
} 
Posteriormente, a Emenda Constitucional n 33 , de 2001, deu nova redação ao artigo 155, acrescentando-lhe novas disposições, inclusive algumas relativas ao tratamento a ser conferido ao gás natural e produtos dele derivados, nos seguintes termos:

"Art. $155[\ldots]$

$\$ 2^{0}[\ldots]$

XII $-[\ldots]$

h) definir os combustíveis e lubrificantes sobre os quais o imposto incidirá uma única vez, qualquer que seja a sua finalidade, hipótese em que não se aplicará o disposto no inciso, $\mathrm{X}, b$;

$[\ldots]$

$\$ 4^{\circ}$ Na hipótese do inciso XII, $h$, observar-se-á o seguinte:

I - nas operações com os lubrificantes e combustíveis derivados de petróleo, o imposto caberá ao Estado onde ocorrer o consumo;

II - nas operaçōes interestaduais, entre contribuintes, com gás natural e seus derivados, e lubrificantes e combustíveis não incluídos no inciso I deste parágrafo, o imposto será repartido entre os Estados de origem e de destino, mantendo-se a mesma proporcionalidade que ocorre nas operações com as demais mercadorias;

III - nas operações interestaduais com gás natural e seus derivados, e lubrificantes e combustíveis não incluídos no inciso I deste parágrafo, destinadas a não contribuinte, o imposto ao Estado de origem."

Desta forma, o ICMS incidente nas operaçōes interestaduais com combustíveis e lubrificantes derivados de petróleo cabe ao Estado onde ocorrer o seu consumo. Diferentemente do gás natural e seus derivados que seguem o mesmo tratamento, em relação ao ICMS, que as demais mercadorias, ou seja, nas operaçōes interestaduais, entre contribuintes, o imposto será repartido entre os Estados de origem e de destino. Enquanto, nas operações interestaduais com gás natural e seus derivados, destinadas a não contribuinte, o imposto caberá ao Estado de origem.

Quanto à imunidade instituída pelo art. $155, \$ 2^{\circ}, \mathrm{X}, b$, da CRFB, entendemos que ela não alcança as operaçōes com gás natural e seus derivados. Neste sentido sempre se orientaram os melhores estudos, que não incluem, dentre as imunidades relativas ao petróleo, tratamento aos produtos derivados do gás natural.

$\$ 1$ ․ Para efeitos dos incisos I e II deste artigo, consideram-se correntes os hidrocarbonetos líquidos derivados de petróleo e os hidrocarbonetos líquidos derivados de gás natural utilizados em mistura mecânica para a produção de gasolinas ou de diesel, de conformidade com as normas estabelecidas pela ANP." 
Marcos André Vinhas Catão, enfaticamente, defende que a imunidade somente abrange o petróleo e seus derivados, nos seguintes termos: "distintamente, e por força da regra excepcional, no caso da comercialização de petróleo e seus derivados, tanto o produto bruto, quanto até mesmo os refinados, têm sua arrecadação redirecionada para o Estado onde se dá o respectivo consumo. Em síntese, a tributação sobre o consumo de petróleo e seus derivados atende então ao que se chama de 'regime de destino', por força do prescrito no art. $155, \S 2 \stackrel{\circ}{,}, \mathrm{b}, \mathrm{b}$, da Constituição Federal. Tal, entretanto, não é o regime juridico-financeiro da totalidade de outros combustiveis, entre os quais a crescente matriz energética, gás natural, os quais, por determinaçāo do texto constitucional, remanesceram na regra de origem". ${ }^{11}$

Verifica-se que o citado autor não fez qualquer distinção temporal relativa à diç̧ão do artigo posteriormente à Emenda Constitucional. Mais do que isso, usa como fundamentação para a distinção o próprio art. $155, \mathbb{2} 2^{\circ}, \mathrm{X}, b$, que não sofreu alteração com a EC n 33/01.

O raciocínio que se deve empregar, tendo como premissa o que se expôs, é simples e inevitável. Sendo o petróleo o hidrocarboneto líquido em seu estado natural, e sendo gás natural todo hidrocarboneto que permaneça em estado gasoso nas condições atmosféricas normais, conclui-se que petróleo não se confunde e nem pode ser igualado a gás natural. Assim, a disposição do art. $155, \$ 2^{\circ}, \mathrm{X}, b$, abrange petróleo e seus derivados (de acordo com a Lei $n^{\circ} 9.478 / 97$, art. $6^{\circ}$, III, produtos decorrentes da transformação de petróleo), não o gás natural. A mesma idéia vale para os combustíveis, quando forem derivados de petróleo (o que, evidentemente, não abrange álcool, óleo de mamona ou GL derivado do gás natural).

A Constituição estabelece imunidade nas operações interestaduais com petróleo e seus derivados, não podendo ser questionada juridicamente por violar a isonomia. Ressalte-se, todavia, que não se institui, na Constituição, imunidade às operaçōes envolvendo gás natural. Interpretação extensiva, a abranger gás natural e produtos oriundos do seu refino, viola a isonomia, ao dar benefício aos Estados consumidores, em detrimento dos produtores.

Sobre este ponto, cumpre trazer à colação os votos proferidos no julgamento, pelo STF, do Recurso Extraordinário 198.088-5/SP. Neste acórdão, esclareceu-se que a norma imunizante do art. $155, \$ 2^{\circ}, X, b$, teve o objetivo de reduzir as desigualdades regionais entre Estados produtores de petróleo e Estados consumidores.

"Salta à vista, com efeito, que objetiva ela eliminar, como fonte geradora de ICMS, os poços de petróleo e as refinarias instaladas em poucos Estados, na medida em que exclui da incidência do tributo as

11 CATÃO, Marcos André Vinhas. Incidência do ICMS no momento da extração do petróleo. (In)constitucionalidade da lei estadual (RJ) $\mathrm{n}^{\circ}$ 4.117/03. In: RIBEIRO, Marilda (Coord.). Estudos $e$ pareceres: direito do petróleo e gás. Rio de Janeiro: Renovar, 2005. p. 534. 
operações destinadas ao abastecimento das demais unidades federadas, prevenindo o agravamento das desigualdades regionais, um dos objetivos fundamentais da República (art. 3º, III, da CF). Prestigiou o constituinte, nesse passo, os Estados consumidores em detrimento dos Estados produtores.

$[\ldots]$

É patente, entretanto, que não se está, no caso, diante de imunidade propriamente dita, mas de genuína hipótese de não-incidência do tributo - como, aliás, se acha expresso no inc. X do $\$ 2^{\circ}$ do art. 155 da CF -, restrita ao Estado de origem, não abrangendo o Estado de destino, onde são tributadas todas as operações que compõem o ciclo econômico por que passam os produtos descritos no dispositivo sob enfoque, desde a produção até o consumo.

Não beneficia, portanto, o consumidor, mas o Estado de destino do produto, ao qual caberá todo o tributo sobre ele incidente, até a operação final. Do contrário, estaria consagrado tratamento desigual entre consumidores, segundo adquirissem eles os produtos de que necessitam, no próprio Estado, ou no Estado vizinho, o que não teria justificativa."12

Segundo Paulo Magalhães da Costa Coelho, ${ }^{13}$ há dois motivos que levaram à instituição desta imunidade: primeiro porque o combustível é insumo que tem repercussão imediata nos custos comerciais e industriais que se transferem com rapidez à sociedade; e, segundo, por uma questão de receita tributária dos Estados mais pobres da Federação que seriam meros receptores do petróleo e seus derivados e da energia elétrica. Igual entendimento é defendido por Roque Antônio Carrazza, ${ }^{14}$ para quem a imunidade em tela visa favorecer os Estados mais pobres da Federação.

A regra da imunidade, portanto, é medida protetiva instituída em favor dos Estados consumidores de petróleo e derivados, e que não se justifica em relação ao gás natural. Como já exposto, e agora se ressalta, a exploração do gás natural pode se dar independentemente da exploraçāo do óleo. Estados com insignificante produção de petróleo - e grandes consumidores do mesmo - podem ser (e muitas vezes são) produtores, em grande quantidade, de gás natural. ${ }^{15} \mathrm{~A}$ extensão para os derivados do gás natural do tratamento estabelecido pela Constituição

\footnotetext{
STF, RE n 198.088-5 / SP, rel. Min. Ilmar Galvāo, DJ 5.9.2003, trecho do voto do relator.

13 COELHO, Paulo Magalhāes da Costa. A questāo da imunidade tributária das operações relativas à circulação interestadual de petróleo e outros derivados. Cadernos de Direito Tributário e Finanças Públicas, $n^{2} 13$, p. 34-35, 1995.

14 CARRAZZA, Roque Antônio. ICMS. 11. ed. São Paulo: Malheiros, 2006.

15 Esta informação pode ser confirmada no site da Agência nacional do Petróleo no endereço <http:// www.anp.gov.br/doc/petroleo/reservas_20051231.pdf>. Acesso em: 3 out. 2006).
} 
Federal ao petróleo não encontra amparo no direito positivo, assim como também é de todo inconveniente, do ponto de vista político, e vai de encontro à intenção do constituinte, originário e reformador, podendo, inclusive, prejudicar aqueles Estados em favor de quem se instituiu a proteção constitucional.

Prosseguindo, pode-se argumentar que se o legislador constituinte pretendesse estabelecer tratamento similar a derivados de petróleo e gás natural, tê-lo-ia feito expressamente, como ocorreu com diversos diplomas legislativos, ou simplesmente faria referência a combustiveis e lubrificantes "obtidos a partir do refino de hidrocarbonetos" ou, ainda, aos "derivados de petróleo, gás natural e demais hidrocarbonetos". Não só não o fez, como ainda traçou regramento diferenciado de forma nítida, e em diversas passagens, como já se logrou demonstrar. ${ }^{16}$

Tem-se, portanto, como legítima a exação oriunda da tributação, pelos Estados produtores, sobre operações interestaduais que tenham por objeto o GLGN. Ao contrário, quando se tratar de operação interestadual que envolva gás liquefeito derivado de petróleo, incide a imunidade instituída pelo inciso $\mathrm{X}$ do $\$ 2^{\circ}$ do art. 155, do Texto Constitucional.

O panorama exposto, é bom que se ressalte, nāo foi criado com a Emenda Constitucional $n^{0} 33 / 2001$. Não foi com o seu advento que se estabeleceu tratamento tributário diferenciado ao petróleo e ao gás natural. As operaçōes interestaduais com gás natural e combustiveis dele derivados sempre foram tributadas com o ICMS, uma vez que a elas não se aplicava a imunidade estabelecida no art. $155, \mathbb{2} 2^{\circ}, X, b$, da Constituição da República.

Em síntese, a tributação das operações com o petróleo não deve ser confundida com aquelas oriundas do gás natural. A Carta Constitucional, em sua redação original, determinou que não incide o ICMS "sobre operaçōes que destinem a outros Estados petróleo, inclusive lubrificantes, combustiveis líquidos e gasosos dele derivados, e energia elétrica" (art. $155, \mathbb{2} 2^{9}$, XII, $b$ ). O gás natural, por sua vez, jamais foi beneficiado pelo constituinte com a regra imunizante de que gozavam os combustíveis derivados do petróleo. Conclui-se, portanto, que, não havendo imunidade, incide o ICMS sobre operações com GLGN.

Tanto é assim que o Supremo Tribunal Federal e o Poder Judiciário do Estado do Rio de Janeiro julgaram no sentido da possibilidade de tributaçāo pelo Estado de origem, independentemente de lei complementar editada ou da celebração de convênio entre os Estados, como será a seguir analisado.

\footnotetext{
16 E nem se diga que o gás natural pode ser considerado derivado do petróleo. Nem do ponto de vista geológico - por ser aquele encontrado, na natureza, em reservatórios apenas gaseíferos, ou junto de reservas de petróleo, não pode ser considerado produto decorrente da transformação do petróleo - e nem do estritamente jurídico (como já se apontou) são idênticos os produtos. Por igual, não se pode igualar o tratamento dispensado ao GL de origem petrolífera ou gasosa, uma vez que é a própria Constituição que confere tratamentos diferentes aos derivados do petróleo e aos do gás natural.
} 


\section{O Protocolo ICMS nº 33, de 12 de dezembro de 2003}

Não obstante o diferente tratamento tributário dispensado ao GL derivado do petróleo (GLP) e ao GL derivado do gás natural (GLGN), por inúmeras vezes tornava-se difícil fazer esta distinção na prática. Isto porque, além de ambos apresentarem as mesmas características físico-químicas, era usual a mistura homogênea do GLP oriundo das duas fontes, resultando-se, portanto, na impossibilidade de identificar a sua origem.

Este problema refletia-se na arrecadação. O conflito, por exemplo, surgia quando numa operação interestadual com GL obtido de uma Unidade de Processamento de Gás Natural (UPGN), o Estado consumidor exigia integralmente o ICMS, uma vez que assumia como premissa que, se o produto era GLP, então era derivado de petróleo. Os Estados produtores, por seu turno, entendiam que, tendo sido este GL obtido a partir de gás natural, o ICMS era devido àquelas Unidades da Federação, não se sujeitando, por óbvio, à tributação como se derivado de petróleo fosse.

Destaque-se, ainda, que, no Estado do Rio de Janeiro, a Petrobras produz GL na REDUC (Refinaria Duque de Caxias) e na unidade de Macaé. Na primeira, a produção é inteiramente dedicada ao mercado interno, de modo que não se coloca o problema. No caso da planta de Macaé, a UPGN não processa petróleo, mas somente gás natural; assim, a priori, toda a produção de GL, oriunda desta planta, é derivada de gás natural.

Tendo essa problemática em vista, os Estados criaram um subgrupo de trabalho no Grupo de Trabalho de Combustíveis na Comissão Técnica Permanente de ICMS (COTEPE) para tratar da questão. Foi proposto, em decorrência dos trabalhos do subgrupo, o Protocolo ICMS n 33/2003, que prevê a seguinte solução:

“Cláusula primeira. Nas operaçōes interestaduais com Gás Liquefeito de Petróleo - GLP, derivado de gás natural tributado na forma estabelecida pelo Convênio ICMS 03/99, deverão ser observados os procedimentos previstos neste Protocolo para a apuração do valor do ICMS devido à unidade federada de origem.

Cláusula segunda. Os estabelecimentos industriais e importadores deverão identificar a quantidade de saída de Gás Liquefeito de Petróleo - GLP derivado de Gás Natural e de Gás Liquefeito de Petróleo - GLP derivado do próprio petróleo, por operação.

$\$ 1^{\circ}$ Para efeito do disposto no 'caput' desta cláusula a quantidade deverá ser identificada proporcionalmente à participação de cada produto no somatório do estoque inicial e nas quantidades produzidas ou importadas tendo como referência o mês imediatamente anterior.

$\$ 2^{\circ}$ No corpo da nota fiscal de saída deverá constar o percentual de GLP derivado de gás natural na quantidade total de saída, obtido de acordo com o disposto no parágrafo anterior. 
$\$ 3^{\circ} \mathrm{Na}$ operação de importação, o estabelecimento importador, por ocasião do desembaraço aduaneiro, deverá quando da emissão da nota fiscal de entrada, discriminar o produto, identificando se é derivado de gás natural ou do petróleo;

$\$ 4^{\circ}$ Relativamente à quantidade proporcional de GLP derivado de Gás Natural, o estabelecimento deverá destacar a base de cálculo e o ICMS devido sobre a operação própria, bem como o devido por substituição tributária, incidentes na operação.

Cláusula terceira. O contribuinte substituído que realizar operaçōes interestaduais com os produtos a que se refere este Protocolo, deverá adotar os seguintes procedimentos:

I - identificar proporcionalmente a participação de cada produto no somatório do estoque inicial e nas quantidades adquiridas tendo como referência o mês imediatamente anterior, preenchendo o relatório constante do Anexo I deste Protocolo;

II - emitir nota fiscal mencionando no seu corpo o percentual de GLP derivado de Gás Natural, na quantidade total de saída, obtido na forma do inciso anterior;

III - indicar no campo 'informações complementares' da nota fiscal de saída os valores da base de cálculo, do ICMS normal e do devido por substituição tributária, incidentes na operação, relativamente à quantidade proporcional de GLP derivado de Gás Natural.

Parágrafo único - Para efeito do disposto no inciso I, nos três primeiros dias de cada mês, será considerada a proporcionalidade utilizada no mês anterior."

O Protocolo citado estabelece uma divisão do GL nas operações, resolvendo a questão ao determinar a definição da proporção do GL de origem petrolífera (GLP) e de origem no gás natural (GLGN). Impōe, portanto, o dever de identificação da proporção de GLP e de GLGN na composição do gás liquefeito que deixa o estabelecimento, a fim de incidir o ICMS sobre a porção composta de GLGN para a unidade federada de origem.

Apesar da resistência de alguns Estados, o Supremo Tribunal Federal assentou a constitucionalidade do Protocolo n 33/03, no julgamento da Ação Direta de Inconstitucionalidade $n^{\circ} 3.103$, proposta pelo Governador do Estado do Piauí. O STF julgou improcedente a ação, declarando constitucional o protocolo, em decisão recente, cuja ementa se transcreve:

“EMENTAS: 1. INCONSTITUCIONALIDADE. Ação direta. Petição inicial. Ilegitimidade ativa para a causa. Correção. Aditamento anterior à requisiçāo das informações. Admissibilidade. Precedentes. É lícito, em açāo direta de inconstitucionalidade, aditamento à petição inicial anterior 
à requisição das informações. 2. INCONSTITUCIONALIDADE. Ação direta. Tributo. ICMS. Operações interestaduais com Gás Liquefeito de Petróleo - GLP, derivado de Gás Natural tributado na forma do Convênio ICMS 03/99. Ato normativo. Protocolo no 33/2003. Cláusulas primeira e segunda. Prescrição de deveres instrumentais, ou obrigaçōes acessórias. Subsistência do regime de substituição tributária. Inexistência de ofensa à Constituição. Ação julgada improcedente. São constitucionais as cláusulas primeira e segunda do Protocolo n⿳ 33/2003, que prescrevem deveres instrumentais, ou obrigações acessórias, nas operações com Gás Liquefeito de Petróleo sujeitas à substituição tributária prevista no Convênio ICMS 3/99."

Do voto do relator, Ministro Cezar Peluso, extraem-se as pertinentes observações quanto ao fato de que o Convênio (i) não regula a incidência monofásica do ICMS; (ii) apenas prescreve deveres instrumentais, como o dever de identificação do gás liquefeito - origem petrolífera ou do gás natural; e de que (iii) a imunidade constitucional às operações interestaduais que tenham por objeto petróleo e seus derivados não alcança o GLGN.

Segundo o Ministro Cezar Peluso, "a cláusula segunda do Protocolo impugnado institui o dever de identificação, nas operações interestaduais, da origem do Gás Liquefeito de Petróleo e, conseqüentemente, permite aplicação da imunidade ao combustível derivado do petróleo e tributação do derivado do gás natural, sob regime de substituição tributária (não sujeito à imunidade do art. 155, X, 'b')".

O Ministro Carlos Ayres Britto, por sua vez, também foi enfático na posição de que não goza o GLGN da imunidade instituída em favor do gás liquefeito de petróleo. Discorre ele que "do exame do Protocolo ICMS n-33/2003, resta claro que ele não cuida de incidência monofásica de ICMS. Apenas, didaticamente, aponta as regras de identificação do GLP de petróleo a serem seguidas nas operações interestaduais. Isso tudo, agregue-se, a fim de permitir a aplicação da regra imunizante sobre o GLP derivado do petróleo (alínea ' $b$ ' do inciso $X$ do art. 155) e a incidência do ICMS sobre as operações com GLP derivado do gás natural".

Como a decisão do Supremo Tribunal Federal, na ADI $n^{\circ} 3.103-1 / P I$, possui efeitos erga omnes e eficácia vinculante (art. $102, \$ 2^{\circ}$, da $C R / 88$ ), não mais é possível a qualquer órgão da Administração Pública ou a outro juiz ou tribunal do país declarar a inconstitucionalidade do referido Protocolo n 33/03. Estão todos adstritos ao pronunciamento do STF, de modo que devem ser aplicadas, à hipótese, as disposiçōes do protocolo.

À vista da decisão do Egrégio Supremo Tribunal Federal, o Judiciário fluminense tem decidido (i) que é constitucional o Protocolo n⿳ 33/2003; (ii) que o GLP derivado do gás natural recebe distinto tratamento em relação ao GLP derivado do petróleo, nāo gozando da imunidade dispensada a este último; (iii) que cabe ao Estado produtor o ICMS incidente nas operaçōes interestaduais que tenham por objeto o GL derivado de gás natural. 
Foi esta a orientação prevalente em recentíssima decisão em Ação de Consignação em Pagamento proposta pela Petróleo Brasileiro S.A. (Petrobrás), proferida pelo Juízo da $11^{\text {a }}$ Vara de Fazenda Pública, verbis:

"Nesse diapasão, certo que o Protocolo legitima a tributação do ICMS, pelos Estados Produtores, sobre as operações interestaduais que tenham por objeto o GLP-GN e que o STF declarou a constitucionalidade do mesmo, reconhecendo, por via de consequiência, o direito do Estado do Rio de Janeiro de tributar o GLP-GN, e tendo em vista o efeito da decisão vinculante, podemos afirmar que o credor no caso em epígrafe é o Estado do Rio de Janeiro.

O descompasso atinge, como se vê, a pretensão dos demais Estados supostamente interessados." 17

E prossegue a decisão:

"A cláusula primeira do Protocolo 33/2001 estabelece que, nas operações interestaduais com Gás Liquefeito de Petróleo - GLP, derivado de Gás Natural tributado na forma estabelecida pelo Convênio ICMS 03/99, deverão ser observados os procedimentos previstos neste protocolo para a apuração do valor do ICMS devido à unidade federada de origem."

Para, então, concluir:

"Destarte, julgo procedente o pedido narrado às tintas da inicial, para declarar que o Estado do Rio de Janeiro é o sujeito passivo da obrigação tributária, devendo ser convertido em renda em seu favor as quantias depositadas e conseqüentemente extinto o crédito tributário (CTN, art. 56 , VIII)."

\section{Conclusão}

Diante de todo o exposto, é possível extrair as seguintes conclusões, enunciadas sob a forma de proposições objetivas.

(i) Em nome da boa técnica, sugere-se uma nova nomenclatura ao Gás Liquefeito de Petróleo derivado de Gás Natural. Isto porque, utilizase o nome GLP (Gás Liquefeito de Petróleo) para designar produto que não é obtido do petróleo e sim a partir de gás natural. A rigor, de-

\footnotetext{
17 Justiça do Rio de Janeiro, Processo no 2004.001.054066-7. Neste processo, a autora, Petrobras, propôs ação de consignação em pagamento em face dos Estados do Rio de Janeiro, Minas Gerais, Espírito Santo, São Paulo, Pernambuco, Paraná, Goiás e Distrito Federal, objetivando declaração judicial acerca de a qual Estado caberia o ICMS incidente sobre as operaçōes interestaduais que tivessem por objeto o GLP derivado de gás natural que produz.
} 
veria ter a denominação de Gás Liquefeito derivado de Gás Natural (GLGN). Assim, evita-se confusōes, já que a incidência do ICMS variará, conforme a origem do gás liquefeito - petróleo ou gás natural.

(ii) A legislação confere tratamento distinto ao petróleo e ao gás natural, tanto na Constituição como nas leis ordinárias que regulam o setor (Lei $\mathrm{n}^{\circ}$ 9.478/97). O gás natural não se inclui entre os derivados de petróleo, razão pela qual não pode receber o mesmo tratamento dispensado a estes últimos. A imunidade instituída pelo art. $155, \$$ $2^{\circ}, \mathrm{X}, b$, da CRFB alcança apenas as operações com petróleo e seus derivados, não sendo aplicável às operações com gás natural e seus produtos derivados, como o GLGN.

(iii) As operações interestaduais que tenham por objeto o GLGN serão tributadas com o ICMS pelo Estado produtor, uma vez que a CRFB não institui tratamento diferenciado para elas, diferentemente do que faz em relação às operações com combustíveis derivados do petróleo.

(iv) O Protocolo ICMS n 33/2003 foi elaborado para solucionar conflitos relativos à tributação da mistura de GLP derivado de petróleo e GLGN, determinando a identificaçāo da proporção de cada produto na composição do gás liquefeito. Cabe ao Estado de origem o ICMS incidente sobre as operaçōes com Gás Liquefeito de Gás Natural.

(v) O Supremo Tribunal Federal reconheceu, na Ação Direta de Inconstitucionalidade $\mathrm{n}^{\mathrm{o}}$ 3.103-1/PI, a constitucionalidade do Protocolo $33 / 2003$.

(vi) A decisão do STF foi em controle concentrado e abstrato de constitucionalidade, gozando de efeitos erga omnes e eficácia vinculante em relação aos demais órgãos do Judiciário e, em especial, aos da Administração Pública.

(vii) Em conseqüência, cabe ao Estado de origem o ICMS incidente sobre as operaçōes com Gás Liquefeito derivado de Gás Natural (GLGN). Neste sentido, o Judiciário do Estado do Rio de Janeiro decidiu a ação consignatória $n^{\circ}$ 2004.001.054066-7, julgando caber ao Rio de Janeiro, Estado produtor, o ICMS sobre operaçōes com GLGN, uma vez que distingue-se das operações com petróleo e seus derivados.

\section{Referências bibliográficas}

CARRAZZA, Roque Antônio. ICMS. 11. ed. São Paulo: Malheiros, 2006.

CATĀO, Marcos André Vinhas. Incidência do ICMS no momento da extração do petróleo. (In)constitucionalidade da lei estadual (RJ) no 4.117/03. In: RIBEIRO, Marilda (Coord.), Estudos e pareceres: direito do petróleo e gás. Rio de Janeiro: Renovar, 2005. 
COELHO, Paulo Magalhães da Costa. A questão da imunidade tributária das operações relativas à circulação interestadual de petróleo e outros derivados. Cadernos de Direito Tributário e Finanças Públicas, nº 13, 1995.

LEMOS, Luiz Antônio de Maia. A estrutura contratual da indústria de transporte de gás. In: RIBEIRO, Marilda (Coord.). Estudos e pareceres: direito do petróleo e gás. Rio de Janeiro: Renovar, 2005. p. 211-212.

MACHADO, Hugo de Brito. Aspectos fundamentais do ICMS. 2. ed. São Paulo: Dialética, 1999.

MARTINS, Ives Gandra da Silva. Cofins - imunidade das operações com derivados de petróleo - inteligência do art. $155, \mathbb{} 3^{\circ} \mathrm{da} C F$ - questões processuais. Cadernos de Direito Constitucional e Ciência Política, nº 11, 1995.

MATTOS, Aroldo Gomes de. Operaçōes interestaduais com petróleo, inclusive lubrificantes, e combustíveis dele derivados. In: ROCHA, Valdir de Oliveira. ICMS: problemas jurídicos. São Paulo: Dialética, 1996.

RIBEIRO, Marilda Rosado de Sá. Introdução à unitização de reservatórios petrolíferos. In: RIBEIRO, Marilda (Coord.). Estudos e pareceres: direito do petróleo e gás. Rio de Janeiro: Renovar, 2005.

SILVEIRA FILHO, Guido Rogério Macedo; OLIVEIRA, Jorge Luiz. Distorções/ contestaçōes tributárias no mercado de combustíveis. In: RIBEIRO, Marilda (Coord.). Estudos e pareceres: direito do petróleo e gás. Rio de Janeiro: Renovar, 2005. 